\title{
PROPHET MODEL IN FINANCIAL PERFORMANCE FORECAST: IMPLEMENTATION IN MANUFACTURING SECTOR
}

DOI: 10.17261/Pressacademia.2021.1470

JEFA- V.8-ISS.4-2021(1)-p.160-166

Ali Yurttabir ${ }^{1}$, Ilker Kiymetli Sen²

${ }^{1}$ Istanbul Commerce University, Institute of Social Sciences, Department of Accounting and Auditing, Sutluce Campus, Istanbul, Turkey. ali.yurttabir@istanbulticaret.edu.tr, ORCID: 0000-0001-8689-3476

${ }^{2}$ Istanbul Commerce University, Faculty of Business, Department of Accounting and Auditing, Sutluce Campus, Istanbul, Turkey. ilksen@ticaret.edu.tr, ORCID: 0000-0001-6175-3397

\begin{tabular}{l}
\hline Date Received: Date Accepted: \\
\hline To cite this document \\
Yurttabir, A., Kiymetli Sen, I.., (2021). Prophet model in financial performance forecast: implementation in manufacturing sector. Journal of \\
Economics, Finance and Accounting (JEFA), 8(4), 160-166. \\
Permanent link to this document: $\underline{\text { http://doi.org/10.17261/Pressacademia.2021.1470 }}$ \\
Copyright: Published by PressAcademia and limited licensed re-use rights only.
\end{tabular}

\section{ABSTRACT}

Purpose- Through processing big data, companies have started to prefer artificial intelligence methods that can reach results faster than classical statistical methods. For this reason, financial performance forecasting studies with artificial intelligence methods have been increasing in recent years. The purpose of this study is to contribute to the gap in the field of financial performance forecasting with the Facebook Prophet model which has not been applied before although there are other time series models in the literature.

Methodology- The study employs Facebook Prophet artificial learning model by choosing the net profit/loss as target variable for financial performance forecasting on Python program with the data of 173 companies in the BIST Manufacturing Sector between 2009 and 2020, obtained from the Public Disclosure Platform.

Findings- After training the 46 periods of the data set, performance matrices of MSE, RMSE and MAPE were measured for the last 2 periods as MSE values between 0.0185 and 25.0147, RMSE values between 0.1361 and 5.0015 and MAPE values between 0.1002 and 4.6634 . In addition to values close to zero, there are also values that move away from zero. The analysis reveals that besides successful predictions, there are also unsuccessful predictions.

Conclusion- It may be concluded that the Facebook Prophet method will save companies time without requiring much effort. To further improve accuracy and performance, creating a mixed artificial intelligence model by leveraging the strengths of multiple models is recommended for further studies.

Keywords: financial performance forecasting, artificial intelligence, time series, Facebook Prophet, BIST manufacturing sector JEL Codes: C22, C45, C53

\section{FINANSAL PERFORMANS TAHMININDE PROPHET MODELI: IMALAT SEKTÖRÜ UYGULAMASI}

\footnotetext{
ÖZET

Amaç- Büyük veriyi işleme noktasında şirketler klasik istatistik yöntemlerinden daha hızlı sonuca ulaşabilecekleri yapay zeka yöntemlerini tercih etmeye başlamışlardır. Bu nedenle son yıllarda yapay zeka yöntemleriyle finansal performans tahmini çalışmaları da giderek artmaktadır. Farklı zaman serisi modelleri ile finansal performans tahmini çalışmaları olmasına rağmen Facebook Prophet modeli ile yapılan çalışmaya literatürde rastlanmadığından alandaki boşluğa katkı sağlanması amaçlanmaktadır.

Yöntem- BIST İmalat Sektöründe yer alan 173 şirketin Kamuyu Aydınlatma Platformu veri tabanından elde edilen $2009-2020$ yılları arasındaki verileri, net dönem kar/zararı hedef değişken olarak seçilerek yapay öğrenme modeli Prophet ile Python programı üzerinde çalışarak finansal performans tahmini yapılmıştır.

Bulgular- Veri setindeki 46 dönem eğitildikten sonra son 2 döneminin tahminine ait MSE değerleri 0,0185 ile 25,0147 arasında, RMSE değerleri 0,1361 ile 5,0015 ve MAPE değerleri ise 0,1002 ile 4,6634 aralığında ölçülmüştür. Sıfıra yakın değerler yanında sıfırdan uzaklaşan değerler de bulunmaktadır. Bu da başarılı tahminlerin yanında başarısız tahminlerin de olduğunu göstermektedir.

Sonuç- Prophet yönteminin çok fazla çaba harcamayı gerektirmeden şirketlere zaman kazandıracağı söylenebilir. Doğruluğu ve performansı daha da geliştirmek için birden fazla modelin güçlü yönlerinden yararlanarak karma bir yapay zeka modeli oluşturmak sonraki çalışmalar için önerilmektedir.
}

Anahtar Kelimeler: finansal performans tahmini, yapay zeka, zaman serisi, Facebook Prophet, BIST İmalat Sektörü. JEL Kodları: C22, C45, C53 


\section{GiRiş}

Finansal performans tahmininde son yıllarda yaygın olarak çeşitli makine öğrenmesi araçları kullanılmaktadır. Özellikle yapay sinir ağları araştırmalarda en çok çalışılan yöntem olarak ortaya çıkmaktadır. 2017 yılında yeni bir zaman serisi tahmin aracı olan Prophet, Facebook tarafından açık kaynaklı olarak kullanıma açılııstır. Diğer yöntemler kadar yaygın olmasa da literatürde zaman serisi tahminlerinde Prophet'in de kullanılmaya başlandığı görülmektedir. Bu çalışmada diğer modelleme araçlarına göre yeni bir modelleme aracı olan Facebook Prophet ile Borsa İstanbul İmalat Sektöründe işlem gören şirketlerin Net Dönem Kar/Zarar tahminini elde etmek için oluşturulan modelin tahmin performansının değerlendirilmesi amaçlanmaktadır.

Bu çalışmada kullanılan veriler Borsa İstanbul'da imalat sektöründe işlem gören 173 şirketin 2009-2020 verileri Kamuyu Aydınlatma Platformundan elde edilmiştir. Net Dönem Kar/Zararı işletmelerin temel performans göstergelerinden biri olarak kabul edildiğinden hem işletmenin performansı hakkında bilgi sahibi olmak isteyen taraflar hem de işletme yöneticileri için önemli bir kalem olduğundan bu araştırmada bağımlı değişken olarak alınmıştır.

Öncelikle literatürde yapılan ulusal ve uluslararası çalışmalara değinilmiştir. Devamında kullanılan veriler, model ve yöntem ele alınarak bulgular sunulmuştur. Sonuç bölümünde modelin performans değerlendirmesi ve önerilere yer verilmiştir.

\section{LITERATÜR}

Finansal performansın ekonomik büyüme üzerine etkili olduğunu pek çok amprik çalışma ortaya koymaktadır (Schumpeter, 1983; Cecchetti ve Kharroubi, 2012; Law ve Singh, 2014; Gergin ve Kıymetli Şen, 2019). Finansal performans belirlemede net karın değişken olarak kullanıldığı çalışmalar bulunmaktadır. Aydemir ve diğerleri (2012) 1990-2009 yılları arasında imalat sektöründeki 73 şirketin verilerini kullanarak borsa fiyatını belirlemede etkin olan finansal rasyoları belirlemeye çalıştıkları çalışma sonucunda rasyoların borsa fiyatı belirlemede düşük etkisi olduğu ancak net kar marjının ise olumlu ve istatistiksel olarak anlamlı etkilediğini bulmuşlardır. Bayrakdaroğlu ve diğerleri (2017), hisse fiyatları ile karlıık oranları arasındaki ilişkiyi göstermeyi amaçladıkları çalışmalarında yatırım kararı verirken net kar marjını ele almanın yatırımcıların kazancına katkı sağladığı sonucuna ulaşmışlardır.

Türkiye'de muhasebe alanında yapılan lisans üstü tezlerin incelendiği Koç ve Yüncü'nün (2020) çalışmasında tek sektör seçilerek yapılan araştırmalarda en çok imalat sektörünün seçildiği görülmüştür. Bu nedenle daha çok araştırmacıya katkı sağlaması amacıyla, bu çalışmada da BísT İmalat sektöründeki şirketlerin 2009-2020 verileri kullanılmıştır.

Facebook Prophet üzerine literatürde yer alan ulusal ve uluslararası çalışmaların 2019-2021 yılları arasında olduğu görülmektedir. Weytjens ve diğerleri (2019) MLP, LSTM, ARIMA ve Prophet yöntemlerini kullanarak nakit akış tahmini yapmışlardır. Çalışmalarında e-ticaret ve havayolları şirketleri, perakendeciler, birkaç bölge ve ülkede satışı olan toplu taşıma firmaları gibi çok sayıda müşterisi ve işlemi olan şirketler için bu yöntemleri kullanarak alacak hesaplarının nakit akışlarını tahmin etmişlerdir. Yaptıkları değerlendirme, bu yöntemlerin kapsamlıı̆ı, esnekliği ve doğruluğu artırdığını göstermektedir. Aquilera ve diğerleri (2019) uyarlanabilir su yönetimi için esnek yeraltı suyu seviyesi tahmininde Facebook'un Prophet tahmin yaklaşımını kullandıkları çalışmada; Prophet'in yeraltı su seviyesini tahmin etmede çoğu yöntemden daha iyi performans göstererek hidrologlar ve su yöneticileri için hızlı ve esnek bir tahmin aracı olduğu yorumunda bulunmuşlardır. Duarte ve Faerman (2019) sağlık acil durum bölümü göstergelerinin zaman serisi tahminlerinin ARIMA ve Prophet ile karşılaştırdıkları çalışmalarında her modelin farklı zaman serisi özellikleri için daha iyi tahminler sağlamak üzere tasarlandığı görüşünü belirtmişlerdir. Facebook günlük olay sayısı, Prophet modeli ayrıştırmasının temeli olan trend, mevsimsellik ve tatillerde benzer zaman serisi özelliklerine sahip bir gösterge olduğundan bu modeli sağlık verilerine uygulamanın onları bu çalışmada motive ettiğini vurgulamışlardır. Samal ve diğerleri (2019) SARIMA ve Prophet Modeli kullanarak zaman serilerine dayalı hava kirliliği tahmini yaptıkları çalışmalarında performans ölçütlerini kullanarak Prophet genel modeli ile Prophet günlük modelinin performansını karşılaştırdıklarında Prophet günlük modelinin Prophet genel modelinden daha doğru tahmin sonuçları sağladığı sonucuna varmışlardır. Covid-19 ile ilgili yapılan tahmin çalışmalarında da Prophet kullanılarak model oluşturulmaya çalışıldığı görülmektedir. Chan (2020) Myanmar Menkul Kıymetler Borsası kapanış fiyatlarının tahmini için ARıMA ve Prophet yöntemlerini karşılaştırdığı çalışmasında analiz sonuçlarına göre, Prophet'in ARIMA'yı üç dönem için geride bıraktığı ve her iki modelin de kısa vadeli tahmin (günlük ve haftalık tahmin) için uygun olduğu sonucuna varmıştır. Bu çalışmanın amacı Myanmar hisse senedi tahminini desteklemek ve zaman serisi modellemesi, ekonomik analiz ve yatırımlar alanındaki araştırmacılara yardımcı olmaktır. Phutela ve diğerleri (2020) lojistik büyüme modeli ile Hindistan'daki Covıd-19'un durağanlığını tahmin ettikleri çalışmalarında Prophet yöntemini kullanmışlardır. Sosyal mesafe, karantina, temaslı izleme gibi alınan çeşitli önleyici tedbirlerin Covid-19'un yayılmasında etkili olup olmadığını ölçmüşlerdir. Prophet tahmin eğrisine göre 10 Temmuz'dan sonra teyit edilen vakaların büyümesinin durağan bir noktaya ulaşacağını göstermişlerdir. Bir başka ARIMA temelli FB-Prophet ile Coivd-19' un küresel ölçekte tahmin çalışmasında, 02/03/2020-20/06/2020 dönemini kapsayan tahmin setlerinin, ilgili belirsizlikte bir artışla birlikte küresel olarak vaka eğiliminde önemli bir artış gösterdiğini bulmuştur (Gaur, 2020). Sevli ve Gülsoy (2020) Covid-19 salgınına yönelik zaman serisi verileri ile Prophet model kullanarak makine öğrenmesi temelli vaka tahmini yaptıkları çalışmalarında gerçek vakalarla karşılaştırarak büyük oranda tutarlı sonuç verdikleri ortaya konmuştur. Uyarlanabilir kalman filtreleme ile FB-Prophet kullanarak maksimum güç talebi tahmininde bulundukları 
çalışmalarında Guo ve diğerleri (2020) deney sonuçlarının geliştirilmiş maksimum güç talebi tahmin algoritmasının ilgili faktörleri kapsamlı bir şekilde dikkate alabileceğini ve zaman serisi tahmininde iyi bir performansa sahip olduğunu gösterdiğini belirtmişlerdir. Madhuri ve diğerleri (2020) ARIMA üzerinde Prophet kullanarak zaman serisi tahmini için hisse senedi piyasası tahmininde bulunmuşlardır. Çalışmalarında müşterilerin bir hisse senedinin belirli hisselerini satın alma veya satma konusunda karar vermelerinde Prophet'in zaman serisi verilerini analiz etmek için kullanılabilecek iyi bir araç olabileceği yorumunda bulunmuşlardır. Güleryüz ve Özden (2020) LSTM ve Facebook Prophet kullanarak Brent ham petrol trendinin tahmini üzerine yaptıkları çalışmada elde ettikleri sonuçlara göre, LSTM modelinin petrol fiyatlarının trendini tahmin etmede daha üstün sonuçlara sahip olduğu görünmektedir. Žunić ve diğerlerinin (2020) gerçek dünya verilerine dayalı başarılı satış tahminleri için Facebook'un Prophet algoritmasını uyguladıkları çalışma, perakende sektöründe gelecekteki satışları doğru bir şekilde tahmin edebilen ve ürün portföyünü beklenen tahmin güvenilirliği düzeyine göre sınıflandırabilen bir çerçeve sunmaktadır. Perakende sektöründe faaliyet gösteren herhangi bir şirket için çok faydalı olacak önerilen çerçeve, Facebook'un Prophet algoritmasına ve geriye dönük test stratejisine dayanmaktadır. Jha ve Pande (2021) FB-Prophet kullanarak süpermarket satışları için zaman serisi tahmin modeli oluşturdukları çalışmada, FB Prophet'in düşük hata, daha iyi tahmin ve daha iyi uyum açısından daha iyi bir tahmin modeli olduğu sonucuna varmışlardır. Akdağ ve Bozma (2021) stok akış modeli ve Facebook Prophet algoritması ile Bitcoin fiyat tahmini yapmışlardır. Stok Akış Oranı'nın modele dâhil edilmesi ile Facebook Prophet algoritması kullanıldığında modelin performansının arttığı sonucuna ulaşılmışlardır. Prophet yönteminin, ARIMA yöntemine göre daha etkin sonuçlar verdiği sonucuna ulaşmışlardır.

\section{VERI VE METODOLOJi}

\subsection{Facebook Prophet Modeli}

Prophet modeli, geliştiricileri Facebook veri bilimi ekibinden Taylor ve Letham (2017) tarafından duyurulan, zaman serilerinin tahmininde kullanılan, Python ve R destekli ve açık kaynak kodlu bir tahmin uygulamasıdır. Bu çalışmada Python 3.9.0 ile çalışılmıştır. Facebook Prophet doğrusal olmayan verilerde yılık, aylık, günlük tahminler yaparken belirtilen tatil günlerini de tahmin hesabına katabilen bir algoritmadır. Prophet'in işleyişindeki sezgisel yaklaşım verinin detaylarına boğulmadan etkili tahminler oluşturabilmeyi sağlar (Taylor ve Letham, 2018). Hem genelleştirilmiş doğrusal modellerden (linear model) hem de eklemeli modellerden (additive model) özellikler taşıyan bir model ve kitaplıktır (Mata, 2020).

Zaman serisini tanımlayan genel formül şu şekildedir:

$y(t)=g(t)+s(t)+h(t)+\varepsilon(t)$

$\mathrm{g}(\mathrm{t})$, zaman serisi değerlerindeki periyodik olmayan değişkenleri modelleme fonksiyonudur. $s(t)$ yıllık, aylık ve haftalık periyodik değişimleri temsil eder. $\mathrm{h}(\mathrm{t})$, tatillerin genellikle düzensiz olarak bir ya da daha çok gün için ortaya çıkardığı etkilerini temsil eder. Genellikle normal dağılım olarak modellenen hata terimi $\varepsilon(\mathrm{t})$, modelde bulunmayan her türlü kendine has değişiklikleri ifade eder (Taylor ve Letham, 2018).

Prophet ile diğer istatistiksel yöntemler arasındaki temel fark, döngüdeki analist yaklaşımıdır. Bu yaklaşım, analistin verilerle ilgili alan bilgilerini, içeriden çalışan istatistiksel yöntemler hakkında herhangi bir bilgisi olmadan tahmin algoritması uygulamasına olanak tanır. Bu nedenle bu yaklaşım, hem istatistiksel tahmin hem de insan uzmanların kararlarına dayanan tahmin yöntemi olan yargısal tahminden yararlanmaya çalışır (Mata, 2020).

\subsection{Veri Seti Seçimi ve Verilerin İşlenmesi}

Borsa İstanbul'da işlem gören 173 imalat sektörü şirketinin 2009-2020 yıllarına ait toplam 48 adet üçer aylık dönem verileri Kamuyu Aydınlatma Platformundan (KAP) alınarak araştırmaya dahil edilmiştir. Farklı modelleme çalışmalarında da kullanılmak üzere belirlenen 8 bağımsız, 1 bağımlı değişken Tablo-1'de görülmektedir.

\section{Tablo 1: Değişkenler}

\begin{tabular}{|c|c|}
\hline Bağımsız Değişkenler & Bağımlı Değişken \\
\hline Hasılat & \multirow{8}{*}{ Net Dönem Kar/Zarar } \\
\hline Net Kar Marjı & \\
\hline Aktif Karlılık Oranı & \\
\hline Özkaynak Karlılık Oranı & \\
\hline Cari Oran & \\
\hline Asit Test Oranı & \\
\hline Brüt Kar/Zarar & \\
\hline Vergi Öncesi Kar/Zarar & \\
\hline
\end{tabular}


Prophet tek değişkenli (univariate) bir yöntem olduğundan sadece tarih ve hedef değişkenden oluşan bir data elde etmek için ön işleme yapılarak bağımlı değişken olan Net Dönem Kar/Zarar kalemi alınmıştır. Ön işleme aşamasında hedef değişkenin tüm yıllardaki toplam değerinin 0 olduğu şirketler veri setinden çıkarılmıştır. Net Dönem Karı/Zararı değerlerinde 0 olanların sayısı toplam sayının \%40'ından fazlaysa o index için işlem yapılmamış ve pas geçilmiştir. Böylece toplam tahmin yapılan şirket sayısı 156 olmuştur. Toplam 48 dönemlik veri setinin ilk 46 dönemi eğitim (train) seti olarak tanımlanmıştır. Son 2 dönemi de tahmin ve performans matrisleri hesaplamak için ayrılmıştır.

\subsection{Performans Matrisleri}

Bu çalışmada modelin performans ölçümü için MSE, RMSE ve MAPE matrisleri kullanılmıştır.

MSE Ortalama Kare Hata (Mean Squared Error): Ortalama kare hatası veya MSE, veri setindeki gerçek değerler ile tahmin değerlerinin farklarının karelerinin toplamı alınarak sonucun örnek sayısına bölünmesi ile elde edilir. Karesi alınmış tahmin hatası değerlerinin ortalaması olarak hesaplanır. Veri setinde aykırı değerler varsa ortalama kare hata değeri yüksek olarak hesaplanabilir (Uğuz, 2019). Ortalama kare hata değeri sıfıra yakın oldukça tahmin modelinin daha iyi performans sergilediği söylenebilir.

$$
\operatorname{MSE}\left(y, h_{\theta}(x)\right)=\frac{1}{n} \sum_{i=0}^{n-1}\left(y_{i}-h_{\theta}\left(x_{i}\right)\right)^{2}
$$

RMSE Kök Ortalama Kare Hata (Root Mean Square Error): Tahmin hatalarının standart sapması olan RMSE bu hataların ne kadar yayıldığını gösterir. Verilere en iyi uyan çizgi etrafında o verilerin ne kadar yoğun olduğunu gösteren RMSE değeri O'dan $\infty$ ’a kadar değişebilir. Negatif yönelimli puanlar ya da diğer bir ifadeyle daha düşük değerlere sahip tahmin modelleri daha iyi performans gösterir. RMSE değerinin sıfır olması modelin hiç hata yapmadığı anlamına gelir (veribilimcisi.com, 2017).

$$
\begin{aligned}
& R M S E=\sqrt{\frac{\sum_{j=1}^{n} e_{j}^{2}}{n}} \\
& R M S E=\sqrt{M S E}
\end{aligned}
$$

MAPE Ortalama Mutlak Yüzde Hata (Mean Absolute Percentage Error): Yüzdelik hataları, birimsiz olma avantajına sahiptir ve bu nedenle, veri kümeleri arasındaki tahmin performanslarını karşılaştırmak için sıklıkla kullanılır (Hyndman ve Athanasopolos, 2018). Geometrik ortalama açısından yorumlanan tahminler için kullanılabilen MAPE'nin çok düşük tahmin değerleri için yüzde hatası \%100'ü geçemez ama çok yüksek tahmin değerleri olduğunda yüzde hatasının üst sınırı yoktur (veribilimcisi.com, 2017).

$$
\text { MAPE }=\frac{100}{n} \sum_{j}^{n} \frac{\left|e_{j}\right|}{\left|A_{j}\right|}
$$

\section{BULGULAR}

Prophet yöntemi ile BIST İmalat Sektöründeki 156 şirkete ait 2009-2020 tarihleri arasındaki 48 adet üçer aylık dönem verileri, 46 dönem eğitildikten sonra son 2 döneminin tahminine ait MSE, RMSE ve MAPE değeri ölçülmüştür. MSE değerleri 0,0185 ile 25,0147 arasında, RMSE değerleri 0,1361 ile 5,0015 ve MAPE değerleri ise 0,1002 ile 4,6634 aralığında ölçülmüştür. Sıfıra yakın değerler yanında sıfırdan uzaklaşan değerler de bulunmaktadır. Bu da başarılı tahminlerin yanında başarısız tahminlerin de olduğunu göstermektedir. 156 şirket içinde modelin en iyi tahmin ettiği 20 şirkete ait değerler Tablo-2'de gösterilmektedir.

Tablo 2: MSE, RMSE ve MAPE Değerleri

\begin{tabular}{|l|l|l|l|c|l|r|}
\hline & Şirket Adı & MSE & Şirket Adı & RMSE & Şirket Adı & MAPE \\
\hline 1 & DEVA & 0,0185 & DEVA & 0,1361 & DEVA & 0,1002 \\
\hline 2 & MNDRS & 0,0284 & MNDRS & 0,1686 & MRSHL & 0,1578 \\
\hline 3 & MRSHL & 0,0352 & MRSHL & 0,1877 & MNDRS & 0,1597 \\
\hline 4 & TTRAK & 0,0372 & TTRAK & 0,1929 & TTRAK & 0,1903 \\
\hline 5 & CCOLA & 0,0736 & CCOLA & 0,2712 & CCOLA & 0,2320 \\
\hline 6 & EGGUB & 0,099 & EGGUB & 0,3146 & DESA & 0,2488 \\
\hline 7 & BFREN & 0,1019 & BFREN & 0,3193 & EGGUB & 0,3145 \\
\hline 8 & DESA & 0,1022 & DESA & 0,3197 & BFREN & 0,3192 \\
\hline 9 & BTCIM & 0,1738 & BTCIM & 0,4169 & BTCIM & 0,4106 \\
\hline 10 & ARSAN & 0,1933 & ARSAN & 0,4397 & SARKY & 0,4185 \\
\hline 11 & HEKTS & 0,2049 & HEKTS & 0,4527 & HEKTS & 0,4255 \\
\hline 12 & SARKY & 0,2085 & SARKY & 0,4566 & ARSAN & 0,4280 \\
\hline
\end{tabular}




\begin{tabular}{|l|l|l|l|l|l|l|}
13 & IHEVA & 0,2473 & IHEVA & 0,4973 & NUHCM & 0,4845 \\
\hline 14 & ALCAR & 0,2522 & ALCAR & 0,5022 & IHEVA & 0,4853 \\
\hline 15 & KENT & 0,2959 & KENT & 0,5439 & ALCAR & 0,4942 \\
\hline 16 & DURDO & 0,3039 & DURDO & 0,5513 & ASLAN & 0,5068 \\
\hline 17 & NUHCM & 0,3175 & NUHCM & 0,5635 & FMIZP & 0,5190 \\
\hline 18 & FMIZP & 0,3303 & FMIZP & 0,5747 & DURDO & 0,5190 \\
\hline 19 & VESTL & 0,3477 & VESTL & 0,5896 & VESTL & 0,5409 \\
\hline 20 & TRKCM & 0,3534 & TRKCM & 0,5945 & KENT & 0,5431 \\
\hline
\end{tabular}

Grafik 1: Deva Holding A.Ş (DEVA) Şirketi Prophet Tahmin Model Grafiği

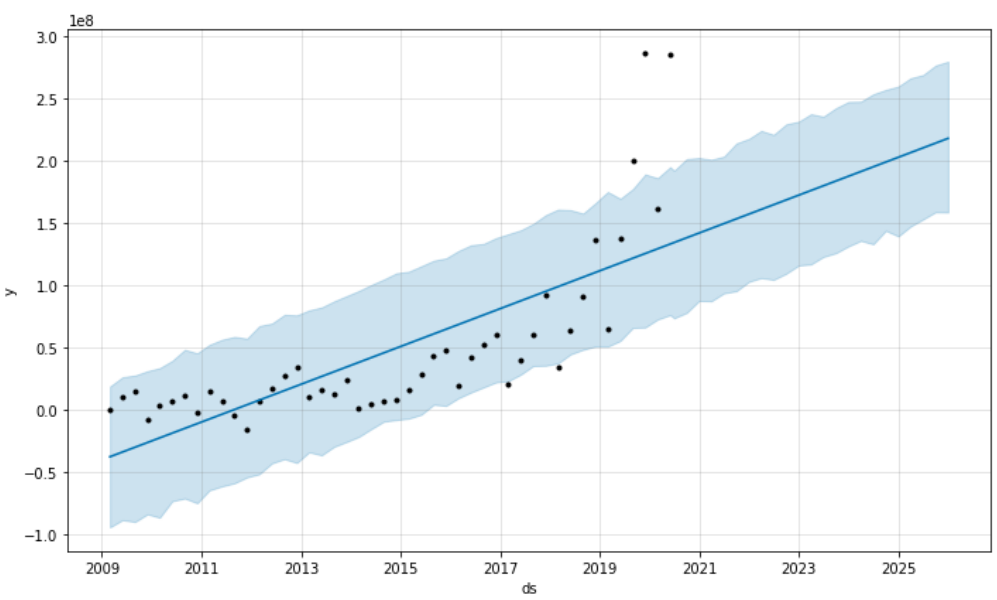

Grafik 2: Bagfaş Bandırma Gübre Fabrikaları A.Ş. (BAGFS) Şirketi Prophet Tahmin Model Grafiği

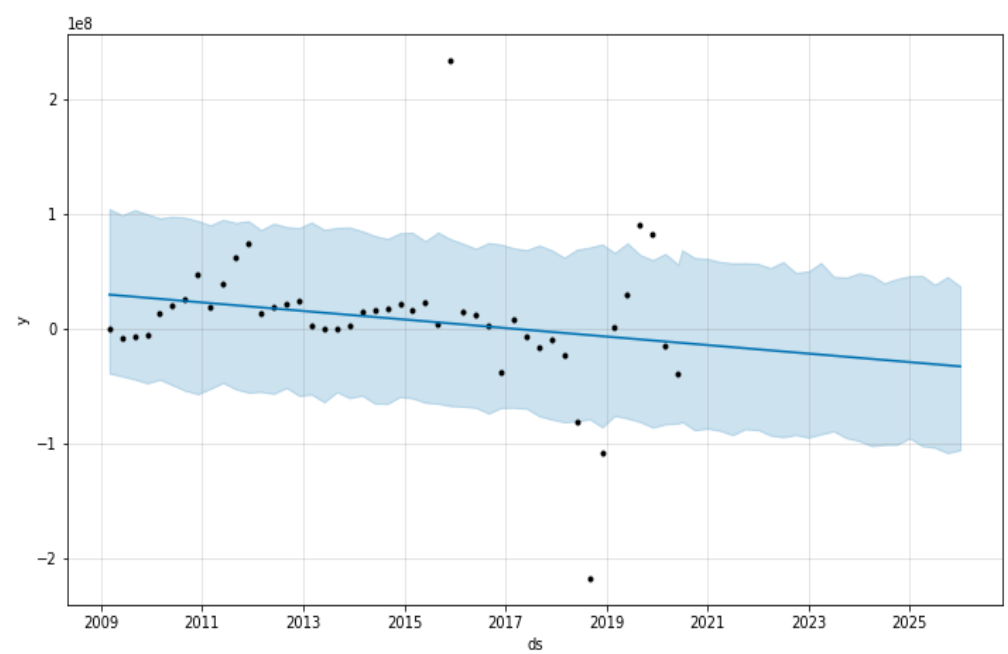

Grafiklerde görülen siyah noktalar gerçek değerleri, mavi çizgiler modelin tahmin ettiklerini, açık maviyle taralı alanlar da tahmin aralıklarını göstermektedir. Prophet modelinin en iyi (sıfıra yakın) tahmin değerine sahip Deva Holding A.Ş (DEVA)'nin grafiğinde 2019'a kadar doğru bir tahmin yaptığı görülmektedir. Ancak 2020 itibari ile gerçek değerlerin tahmin aralı̆̆ının dışında gerçekleştiği görülmektedir. Bu durumun tüm dünyayı etkileyen Covid-19 pandemisinden kaynaklandığı söylenebilir. Prophet modelinin en düşük (sıfırdan uzak) tahmin değerine sahip Bagfaş Bandırma Gübre Fabrikaları A.Ş. (BAGFS)'nin grafiğine bakıldığında ise gerçek değerlerin çok fazla inişli çıkışlı olduğu görülmektedir. Bu durum tahmin başarısını olumsuz etkilemektedir. Deva Holding A.Ş (DEVA) şirketinde 2025 yılına kadar grafikte dengeli artan bir ivme gözlenirken Bagfaş Bandırma Gübre Fabrikaları A.Ş. (BAGFS) şirketi tahminlerinde düşen bir ivme görülmektedir

\section{SONUÇ VE DEĞERLENDIRME}

Finansal performans tahmini, şirket yönetiminin karar verme süreçlerinde öncü bir rol oynadığından belirli bir güven düzeyinde tahmin yapmak önemlidir. Zaman serisi analizi, herhangi bir işletme için kritik olan bir dizi metrik veri noktasının 
zamana dayalı modellerinin anlaşımasına yardımcı olur. Bu çalışmada sunulan Facebook Prophet yöntemiyle zaman serisi modellemesi, tek değişkenli gerçek zaman serisi seviyelerinin büyüme oranlarını analiz ederek tahminin elde edilmesini sağlamaktadır. Bu yönüyle diğer zaman serisi tahmin yöntemlerinden daha hızı ve üretken olduğu söylenebilir. Literatürde Facebook Prophet ile zaman serisi tahmini çalışmaları klasik istatistiki zaman serisi modellemelerine ve diğer yapay zeka yöntemlerine nispeten daha az bulunmaktadır. Finansal performans tahmininde ise Facebook Prophet yöntemiyle bir çalışmaya rastlanmamış olması nedeniyle bu çalışma ile alandaki boşluğa katkı sağlamak amaçlanmıştır. MSE, RMSE ve MAPE performans matrisleri, basitlikleri, son derece sezgisel yorumlamaları ve verilerde uç noktalar olmadığında iyi çalıştıkları gerçeği nedeniyle bu çalışmada kullanım için seçilmiştir. İmalat sektöründe faaliyet gösteren tüm şirketler tek tek incelenmiştir ancak makale kapsamında modelin en yüksek ve en düşük performans gösterdiği şirketler üzerinde örnekler yansıtılmıştır. Özellikle gerçek değerler ile tahminler arasında yüksek uyum gösteren şirketlerin gelecek seneler için tahminlerde de gerçek değerlerle yüksek uyumlu olacağı öngörülmektedir.

Şirketlerin tahmine dayalı analiz sağlayan çok sağlam bir veri bilimi ekibine sahip olmaması durumunda Facebook Prophet yöntemiyle model oluşturmak çok yararlı olacaktır. Sinir Ağları gibi algoritmalar, daha doğru tahminler üretebilse de çok daha fazla veri işleme ve hesaplama gücü gerektirir. Prophet yönteminin çok fazla çaba harcamayı gerektirmeden şirketlere zaman kazandıracağı söylenebilir. Doğruluğu ve performansı daha da geliştirmek için birden fazla modelin güçlü yönlerinden yararlanarak karma bir model oluşturmak sonraki çalışmalar için önerilmektedir. Ayrıca sadece imalat sektöründe faaliyet gösteren şirketler üzerinde yapılan bu çalışma diğer sektörlerde faaliyet gösteren şirketler için de gerçekleştirilebilir.

\section{KAYNAKÇA}

Aguilera, H., Albert, C. G., Fernández, N. N., \& Kohfahl, C. (2019). Towards flexible groundwater-level prediction for adaptive water management: using Facebook's Prophet forecasting approach. Hydrological Sciences Journal/Journal des Sciences Hydrologiques, 64(12), 1504-1518, DOI: 10.1080/02626667.2019.1651933

Akdağ, M., \& Bozma, G. (2021). Stok akış modeli ve facebook prophet algoritması ile bitcoin fiyatı tahmini. Uluslararası Ekonomi, İşletme ve Politika Dergisi, 5 (1), 16-30. DOI: 10.29216/ueip.878925

Aydemir, O., Ögel, S., \& Demirtaş, G. (2012). Hisse senetleri fiyatlarının belirlenmesinde finansal oranların rolü. Yönetim ve Ekonomi Dergisi, 19(2), 277-288.

Bayrakdaroğlu, A., Mirgen, C., \& Kuyu, E. (2017). Relationship between profitability ratios and stock prices: an empirical analysis on BIST-100. PressAcademia Procedia, 6 (1), 1-10. DOI: 10.17261/Pressacademia.2017.737

Cecchetti, G., \& Kharroubi, E. (2012). Reassessing the impact of finance on growth. BIS Working Papers. ISSN 1682-7678

Chan, W. N. (2020). Time series data mining: comparative study of ARIMA and Prophet methods for forecasting closing prices of Myanmar Stock Exchange. Journal of Computer Applications and Research, 1(1), 75-80.

Duarte, D., \& Faerman, J. (2019). Comparison of time series prediction of healthcare emergency department indicators with ARIMA and Prophet. Computer Science \& Information Technology (CS \& IT) Computer Science Conference, 123-33, https://doi.org/10.5121/csit.2019.91810

Gaur, S. (2020). Global forecasting of Covid-19 using ARIMA based FB-Prophet. International Journal of Engineering Applied Sciences and Technology, 5(2), 463-467.

Gergin, B., \& Kıymetli Şen, İ. (2019). Kurumsal yönetim endeksinde yer almanın bankaların performansına etkisi: Borsa İstanbul'da bir araştırma. Muhasebe Bilim Dünyası Dergisi, 21(4), 956-978. doi:10.31460/mbdd.562606

Guo, C., Ge, Q., Jiang, H., Yao, G., Hua, Q. (2020). Maximum power demand prediction using fbprophet with adaptive Kalman filtering. IEEE Access, 8: 19236-19247. https://doi.org/10.1109/ACCESS.2020.2968101

Güleryüz, D. \& Özden, E. (2020). The prediction of brent crude oil trend using LSTM and facebook Prophet. Avrupa Bilim ve Teknoloji Dergisi, (20), 1-9. DOI: 10.31590/ejosat.759302

Hyndman, R. J., \& Athanasopoulos, G. (2018). Forecasting: Principles and Practice. Australia: OTexts, ISBN 978-0-9875071-1-2

Jha, B. K., \& Pande, S. (2021). Time Series Forecasting Model for Supermarket Sales using FB-Prophet. 20215 th International Conference on Computing Methodologies and Communication (ICCMC), 547-554, Erode, India.

Koç, B., \& Yüncü, A. B. (2020). Muhasebe alanında 2004-2018 yılları arasında hazırlanmış lisansüstü tezlerin incelenmesi. Muhasebe Enstitüsü Dergisi (62), 63-75.

Law, S. H., \& Singh, N. (2014). Does too much finance harm economic growth? Journal of Banking and Finance, 41, 36-44.

Madhuri, C., Chinta, M., \& Kumar, V. (2020). Stock Market Prediction for Time-series Forecasting using Prophet upon ARIMA. 7th International Conference on Smart Structures and Systems (ICSSS), Chennai, India, 317-321.

Mata, A. G. (2020). A Comparison Between LSTM and Facebook Prophet Modles: A Fianacial Forecasting Case Study. Universital Oberta de Catalunya. 
Phutela, N., Bakshi, A., \& Gupta, S. (2020). Forecasting the Stability of COVID-19 on Indian Dataset with Prophet Logistic Growth Model. Research Square, https://doi.org/10.21203/rs.3.rs-32472/v1

Samal, K. R., Babu, K. S., Das, S. K., \& Acharaya, A. (2019). Time Series based Air Pollution Forecasting using SARIMA and Prophet Model. ITCC 2019, Proceedings of the 2019 International Conference on Information Technology and Computer Communications, 80-85.

Schumpeter, J.A. (1983). The Theory of Economic Development, An Inquiry into Profits, Capital, Credit, Interest, and the Business Cycle Transaction Publishers, New Brunswick (U.S.A) and London (U.K), ISBN:0-87855-698-2

Sevli, O., \& Başer, V. G. (2020). Covid-19 salgınına yönelik zaman serisi verileri ile Prophet model kullanarak makine öğrenmesi temelli vaka tahminlemesi. Avrupa Bilim ve Teknoloji Dergisi, 827-835, DOI: 10.31590/ejosat.766623

Taylor, S. J., \& Letham, B. (2017). Prophet: Forecasting at Scale Facebook. Eylül 29, 2021 tarihinde https://facebook.github.io/prophet/ adresinden alındı.

Taylor, S. J., \& Letham, B. (2018). Forecasting at Scale. The American Statistician, 72(1), 37-45. doi:10.1080/00031305.2017.1380080

Uğuz, S. (2019). Makine Öğrenmesi Teorik Yönleri ve Python Uygulamaları ile Bir Yapay Zeka Ekolü. Ankara: Nobel Akademik Yayıncılık, ISBN:978-605-033-176-9.

VeriBilimcisi.com. (2017, Temmuz 14). https://veribilimcisi.com/. Eylül 10, 2021 tarihinde Veri Bilimcisi: https://veribilimcisi.com/2017/07/14/mse-rmse-mae-mape-metrikleri-nedir/ adresinden alındı.

Weytjens, H., Lohmann, E., \& Kleinsteuber, M. (2019). Cash flow prediction: MLP and LSTM compared to ARIMA and Prophet. Electronic Commerce Research, 21, 371-391, Issue Date (2021), DOI:10.1007/S10660-019-09362-7

Žunić, E., Korjenić, K., Hodžić, K., \& Đonko, D. (2020). Applicatıon of facebook's Prophet algorithm for successful sales forecastıng based on real-world data. International Journal of Computer Science \& Information Technology, 12(2), 23-36, DOI: 10.5121/ijcsit.2020.12203 